\title{
Tissue Replacement Gingival Prosthesis in the Treatment of Esthetic and Functional Deficit: An Atypical Case Report
}

\author{
${ }^{1}$ Nettemu Sunil Kumar, ${ }^{2}$ Nettem Sowmya \\ ${ }^{1}$ Co-ordinator and Assistant Professor, Department of Periodontics, Faculty of Dentistry, Melaka-Manipal Medical College, Melaka, Malaysia \\ ${ }^{2}$ Assistant Professor, Department of Periodontics, Faculty of Dentistry, Melaka-Manipal Medical College, Melaka, Malaysia
}

Correspondence: Nettemu Sunil Kumar, Co-ordinator and Assistant Professor, Department of Periodontics, Faculty of Dentistry Melaka-Manipal Medical College, Jalan Batu Hampar, Bukit Baru, Melaka-75150, Malaysia, e-mail: nettemsunil@gmail.com

\section{ABSTRACT}

Tissue replacement gingival prosthesis is a simple, noninvasive procedure employed to replace large volumes of lost soft tissue architecture while overcoming the pitfalls of surgical treatment modalities. A removable gingival prosthesis has a definite set of superior advantages compared to the extensive surgical treatment options or the employment of a fixed prosthesis. The removable gingival prosthesis helps to render an esthetically pleasing and functional restoration which is economical and less time-consuming for patients who report with large areas of esthetic and functional deficits. This case report highlights the fabrication of a light-weight design of removable gingival veneer to effectively mask the large area of tissue distortion whilst achieving superior esthetics.

Keywords: Gingival veneer, Removable prosthesis, Esthetics.

\section{INTRODUCTION}

Growing awareness has led to the understanding that the dental esthetics is based not only on the 'white component' of the restoration but also on the 'pink component' surrounding the natural teeth and their replacements. O ver the years, the gingival prostheses have taken different forms and dimensions and numerous authors have described their various uses and methods of construction. ${ }^{1-10}$ Removable prosthetic replacements are especially useful, when a large volume of tissue requires replacement, with proper cleaning still feasible. A Iso, an ideal tissue contour can be created without disturbing the other fixed dental units. Periodontal disease, trauma and congenital defects frequently pose as the etiological factors in effecting both soft tissue and hard tissue defects compounded with esthetic problems. ${ }^{11}$ A $n$ understanding of the form and shade requirements is essential for fabrication of a gingival prosthesis that offers a good intraoral retention and satisfaction for the patient as well as the clinician.

This case report presents an unusual clinical scenario which was treated successfully, with the fabrication of a gingival prosthesis to mask the esthetic and functional deficit.

\section{CASE REPORT}

A 45-year-old female patient reported to the Department of Periodontology presenting with a chief complaint of discolored and irregular appearance of the gums in the upper right side region of the mouth noticed since past 8 years. On eliciting the dental history, the patient revealed that she had undergone extraction of multiple teeth due to extensive dental caries and had undergone restorations of few teeth. The medical and social histories of the patient were noncontributory. Intraoral clinical examination revealed a bluish discoloration of the gingiva extending horizontally between the midportion of the right central incisor up to the right canine region and vertically from the marginal gingiva up to the depth of the vestibule, beyond the mucogingival junction (Fig. 1). The gingival surface appeared firm but presented a depressed and corrugated surface signifying marked resorption of the horizontal component of buccal bone. The patient did not give any history of trauma but reported to have undergone root canal treatment and crown placement of maxillary right lateral incisor and canine 10 years back due to dental caries. The patient also explained that a silver color restoration was used to restore the teeth, suggestive

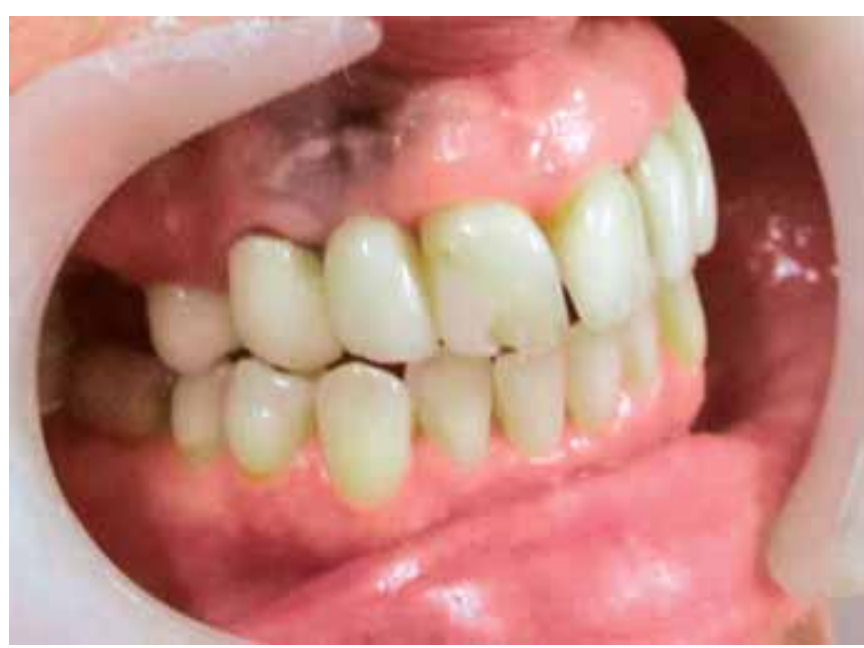

Fig. 1: Preoperative intraoral view 
of a silver amalgam restoration induced amal gam tattoo in that region.

A dvantages and disadvantages were listed out and different treatment options were explained to the patient. Hard tissue grafting using autogenous block bone graft followed by a second surgical procedure of soft tissue augmentation was considered as an option, but discarded due to multiple negative factors including the need for multiple surgical procedures, morbidity associated with the second surgical site, ${ }^{11}$ longer healing time, enhanced patient discomfort, large volume of tissue required to be harvested and unpredictability of the final results. The patient preferred a noninvasive treatment with an end result of achieving superior esthetics. Taking the patient's request into consideration, a thin, lightweight removable gingival prosthesis was finalized as the treatment option. Informed consent was obtained from the patient.

A $n$ impression was obtained using polyether impression material (Impregum, ESPE America Inc., Norristown) and poured in type IV die stone (Die-K een, H eraeus-K ulzer). Shade selection was done. An intraoral try-in of a wax-up was performed using red college-wax (M etrowax, M etrodent, United Kingdom) (Fig. 2). This served as a guide and to facilitate assessment of the retention and results of the final prosthesis. The undercuts present as a result of the corrugated surface architecture of gingiva were utilized to achieve additional retention of the gingival prosthesis in place. The patient was comfortable with the wax-up model and this was then duplicated to fabricate a removable prosthesis. The gingival prosthesis was made from a mixture of pink and clear acrylic in a 30:70 ratio $^{12}$ with mild staining to achieve color matching with the surrounding tissues. Two removable prostheses were fabricated with minimal shade variations and after try-in, the patient was satisfied with the esthetic results and retention of both the gingival veneers and decided to keep both (Figs 3 and 4).

\section{DISCUSSION}

In this current case scenario, the treatment plan was decided upon as the fabrication of a removable prosthesis excluding

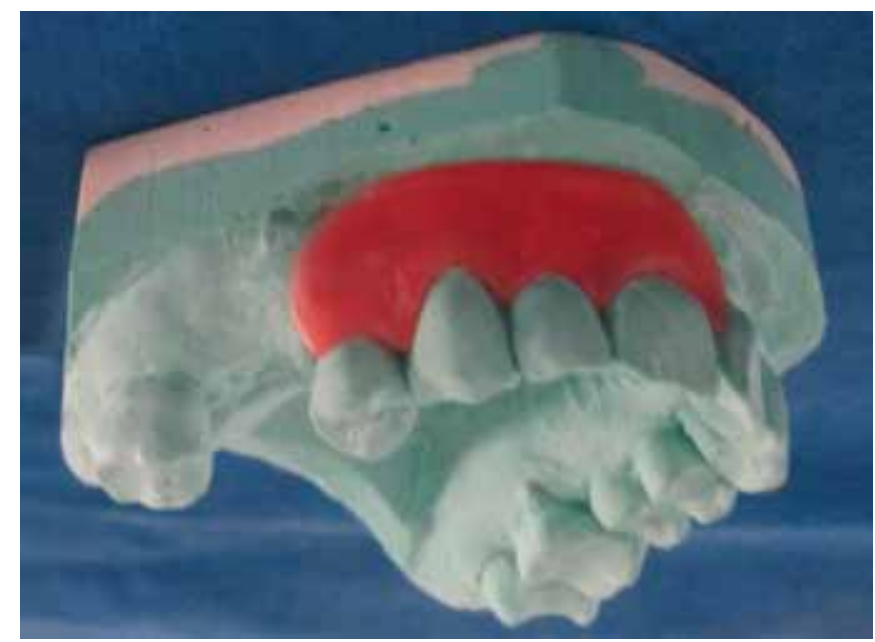

Fig. 2: Wax-up prepared for intraoral try-in procedure

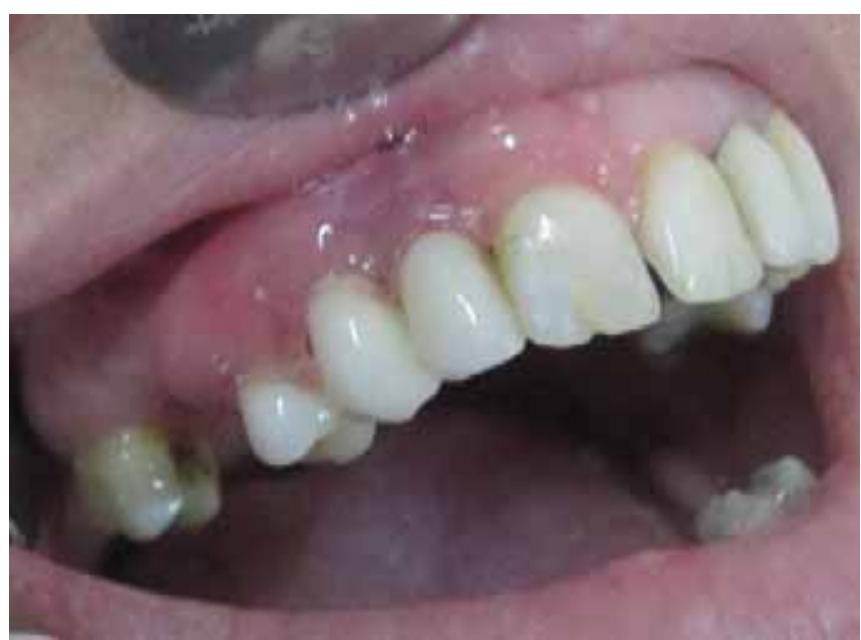

Fig. 3: Final removable gingival prosthesis in place

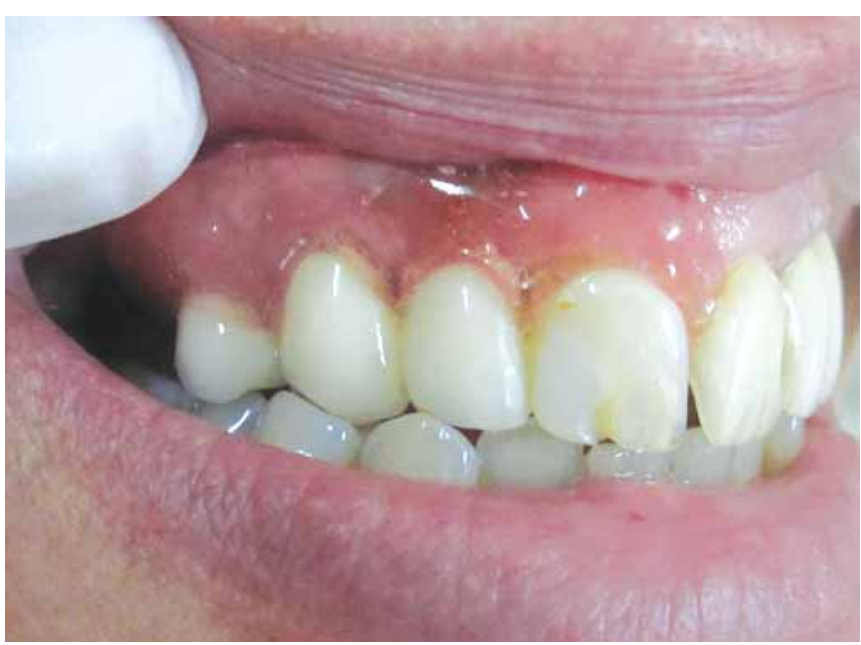

Fig. 4: Second final removable gingival prosthesis in place

the other treatment options of fabricating a fixed prosthesis or the employment of a surgical therapy. In contrast to a fixed prosthesis, a removable gingival prosthesis possessed numerous advantages with the ability to replace a large volume of tissue without disturbing the other dental units, creation of an ideal tissue contour and esthetics and finally, facilitating through cleaning and maintenance of oral hygiene. ${ }^{1} \mathrm{~A} \mid \mathrm{s}$, the retentive component while utilizing a fixed prosthesis, may be compromised as the interproximal areas must be left open for rendering the prosthesis cleanable. Finally, the tissue portion of the fixed prosthesis cannot be adjusted whenever required and hence, the ability to retrofit is retarded compared to a removable gingival prosthesis. While weighing the pros and cons of utilizing a surgical treatment option over the removable gingival prosthesis, for this exacting case scenario, the removable gingival prosthesis had a definite set of superior advantages compared to the extensive surgical treatment options. Surgical treatment procedures are highly successful and can mimic original tissue contours when only a small volume of tissue reconstruction is required. M inor procedures including papillary reconstruction or grafting procedures involving soft and hard tissue augmentations procedures require 
a definite surgical intervention. But the limitations of the surgical approach include the concurrent surgical costs, postoperative discomfort and healing time and the unpredictability of the surgical outcome. Also, the morbidity associated with the second surgical donor site and accompanying possible intraoperative and postoperative complications are avoided.

Removable gingival prostheses can be made using different materials and methods of fabrication and should possess adequate retention to avoid displacement during mastication, speech and soft tissue movements. Ideal tissue contours are waxed, processed and then shade-matched to the surrounding tissues to provide an esthetically pleasing, functional restoration. ${ }^{1}$ The procedure is simple, noninvasive, economical and less time-consuming for both the patient and clinician.

\section{CONCLUSION}

This case report highlighted the fabrication of a sleek lightweight and removable type of gingival prosthesis for the reconstruction of a large volume of lost gingival architecture, while accomplishing adequate retention and finer esthetic results. The corrugated tissue surface was used to advantage for achieving retention and at the same time, masking the surface to the exterior. This procedure helps to render a noninvasive, economical and less time-consuming treatment to patients who report with large areas of esthetic and functional deficits. This type of prosthesis has a definite advantage over the surgical therapeutic modality as well as fixed prosthetic replacement therapy.

\section{REFERENCES}

1. Izchak B arzilay, Irene Tamblyn. Gingival prostheses: A review. J Can Dent Assoc 2003;69(2):74-78.

2. Tallents RH. A rtificial gingival replacements. Oral Health 1983; 73(2):37-40.

3. B otha PJ, Gluckman HL. The gingival prosthesis: A literature review SADJ 1999;54(7):288-90.

4. Friedman M J. Gingival masks: A simple prosthesis to improve the appearance of teeth. Compend Contin Educ Dent 2000; 21(11):1008-16.

5. Blair F M , Thomason J M , Smith DG. The flange prosthesis. Dent Update 1996;23(5):196-99.

6. M ekayarajjananonth T, K iat-amnuay S, Sooksuntisakoonchai N, Salinas TJ. The functional and esthetic deficit replaced with an acrylic resin gingival veneer. Q uintessence Int 2002;33(2): 91-94.

7. Greene PR. The flexible gingival mask: An aesthetic solution in periodontal practice. Br Dent J 1998;184(11):536-40.

8. Priest GF, Lindke L. Gingival-colored porcelain for implantsupported prostheses in the aesthetic zone. Pract Periodontics A esthet D ent 1998;10(9):1231-40.

9. Hannon SM , Colvin CJ , Zurek DJ. Selective use of gingival-toned ceramics: Case reports. Quintessence Int 1994;25(4):233-38.

10. Brygider RM. Precision attachment-retained gingival veneers for fixed implant prostheses. J Prosthet Dent 1991;65(1):118-22.

11. A A lani, A M aglad, F N ohl. The prosthetic management of gingival aesthetics. B ritish Dental Journal 2011;210:63-69.

12. Savage $\mathrm{K} O, \mathrm{~N}$ w ohator $\mathrm{SO}, \mathrm{A}$ yanbadejo PO. Gingival prosthesis: A $n$ alternative to surgery in multiple site gingival recession. Nigerian Quarterly J ournal of Hospital M edicine 2005;15(4): 184-85. 